\title{
Ethical questions identified in a study of local and expatriate responders' perspectives of vulnerability in the 2010 Haiti earthquake
}

\author{
Evelyne Durocher, ${ }^{1,2}$ Ryoa Chung, ${ }^{3}$ Christiane Rochon, ${ }^{4}$ Jean-Hugues Henrys, ${ }^{5}$ \\ Catherine Olivier, ${ }^{6}$ Matthew Hunt ${ }^{1,2}$
}

${ }^{1}$ Faculty of Medicine, School of Physical and Occupational Therapy, McGill University, Montréal, Québec, Canada ${ }^{2}$ Centre for Interdisciplinary Research in Rehabilitation, Montréal, Québec, Canada ${ }^{3}$ Département de philosophie, Université de Montréal, Montréal, Québec, Canada ${ }^{4}$ École de service social, Université de Montréal, Montréal, Québec, Canada ${ }^{5}$ Faculté de Médecine et des Sciences de la Santé, Université Notre Dame d'Haïti, Port-auPrince, Haïti

${ }^{6}$ Département de médecine sociale et préventive, École de santé publique, Université de Montréal, Montréal, Québec, Canada

Correspondence to Dr Evelyne Durocher,

Department of Occupational Science and Occupational

Therapy, Rehabilitation Sciences Institute, University of Toronto 500 University Avenue, Suite

160 Toronto, Ontario, Canada, M5G 1V7

evelyne.durocher@utoronto.ca

Received 12 May 2015 Revised 28 November 2016

Accepted 6 January 2017

Published Online First

24 February 2017

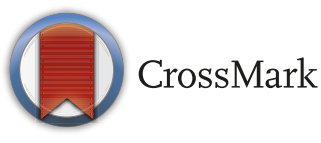

To cite: Durocher $\mathrm{E}$

Chung R, Rochon C, et al.

$J$ Med Ethics

2017:43:613-617.

\section{ABSTRACT}

Background Situations of disaster that prompt international humanitarian responses are rife with ethical tensions. The 2010 Haiti earthquake caused great destruction and prompted a massive humanitarian response. The widespread needs experienced by the population and the scale of the response inevitably rendered priority-setting difficult, and gave rise to ethical challenges.

Purpose This paper presents four ethical questions identified in the analysis of a study on vulnerability and equity in the humanitarian response to the 2010 Haiti earthquake.

Methods Using interpretive description methodology, the interdisciplinary research team analysed 24 semistructured in-depth interviews conducted with expatriate and Haitian health workers and decision-makers involved in the response.

Results Ethical questions identified through the analysis were: (1) How should limited resources be allocated in situations of widespread vulnerability and elevated needs? (2) At what point does it become ethically problematic to expend (considerable) resources to sustain expatriate disaster responders? (3) How ought rapid and reactive interventions be balanced with more deliberated and coordinated approaches? (4) What trade-offs are justified when interventions to address acute needs could contribute to long-term vulnerabilities?

Discussion The questions arise in light of an immense gap between available resources and widespread and elevated needs. This gap is likely unavoidable in largescale crises and may be a source of ethical distress for both local and international responders. The analysis of ethical questions associated with crisis response can advance discussions about how relief efforts can best be designed and implemented to minimise ethical distress and improve assistance to local populations.

\section{INTRODUCTION}

Situations of disaster, war or disease outbreak that prompt international humanitarian responses are rife with ethical tensions. ${ }^{1}$ Prominent sources of ethical questions include triage decisions and the need to quickly determine how limited resources should be allocated in situations of overwhelming need. ${ }^{1-4}$ The scope of humanitarian responses also involves choices to allocate resources at broader levels, including decisions about where to initiate projects, when and how to end them as well as determinations of which populations or projects will be prioritised, and which will not be addressed, or may even be harmed by the approach taken. ${ }^{15-8}$ An additional source of ethical complications relates to power differentials within communities and between providers and recipients of care. ${ }^{18-10}$ These challenges may lead to ethical distress for individuals involved in humanitarian responses, especially when individuals must make choices and all options require something of ethical significance be relinquished. ${ }^{11}$ Despite the breadth of the humanitarian literature, few empirical studies examine ethical issues related to vulnerability, the prioritisation of needs and the distribution of limited resources in the context of disaster responses. ${ }^{3}$ Although definitions vary, vulnerability is broadly conceptualised as a state of susceptibility to harm, which at times may be associated with an inability to protect oneself from risks. ${ }^{12-16}$

The 2010 Haiti earthquake caused great destruction and prompted one of the most significant humanitarian responses of the past decade. The earthquake occurred in a context of widespread poverty, elevated vulnerability and fragile infrastructure-characteristics that can be traced to political and historical patterns and antecedents. ${ }^{17} 18$ The earthquake resulted in more than 220000 deaths, more than 300000 people injured and more than 1500000 people becoming homeless, ${ }^{19}$ thus prompting grave public health concerns including among other issues a lack of access to drinking water, food, shelter or basic medical care, all of which greatly exacerbated the risk of disease. $^{20}$ The disaster triggered a massive international response involving over 1000 relief organisations ${ }^{21}$ and more than US\$4 billion pledged for relief and reconstruction. ${ }^{22}$ The scale of the response, and the widespread and elevated needs experienced by the population, inevitably rendered coordination and priority-setting difficult, and gave rise to ethical challenges. In this paper, we discuss ethical questions that were identified during the analysis of interviews conducted with Haitian and expatriate responders and decision-makers in the context of a study on vulnerability and equity in the 2010 earthquake response.

\section{METHODS}

This paper is part of a broader qualitative study exploring perspectives of Haitian and international individuals involved in the 2010 Haiti earthquake 
response. $^{23}$ Using interpretive description methodology, ${ }^{24}$ we analysed participants' perspectives related to vulnerability and equity in the earthquake response.

Participant recruitment began via email invitations to nongovernmental organisations (NGOs) and to individuals in the investigators' professional networks. The Unité de Recherche et d'Action Médico-Légale facilitated recruitment in Haiti by suggesting potential participants. Additional participants were also recruited based on recommendations of earlier participants. Participants included 6 former Haitian government officials or decision-makers, 5 Haitian healthcare professionals working with international or national NGOs, 3 Haitian healthcare professionals who did not work with NGOs and 10 expatriate healthcare professionals or healthcare coordinators involved in the earthquake response through their work with an NGO. Haitian and expatriate healthcare professionals included physicians, surgeons, dentists and allied healthcare professionals.

The data consisted of 24 in-depth interviews, two-thirds of which were conducted in person and the remainder by telephone or Skype. Interviews were conducted in French or in English depending on participant preferences and averaged $60 \mathrm{~min}$ in length. The semi-structured interview guide was based on a literature review and refined following a pilot interview. Interviews were transcribed and transcripts were reviewed to increase accuracy.

The researchers' diverse perspectives and their comprehensive understanding of the data enabled them to synthesise meanings and theorise relationships. Consistent with interpretive descriptive methodology, ${ }^{24}$ through this process, preliminary interpretations were tested, questioned and reconceptualised into the findings presented below. Ethics approval was obtained from research ethics committees at McGill University and the University of Montréal, as well as from the National Bioethics Committee of Haiti.

\section{RESULTS}

Four prominent ethical questions related to vulnerability were identified through the analysis process. The questions reflect both implicit and explicit ethical concerns raised in the participants' narratives. The questions encompass ethical tensions at both broader or macro levels, as well as at micro levels.

\section{How should limited resources be allocated in situations of widespread vulnerability and elevated needs?}

In the wake of the earthquake, the population experienced elevated and widespread levels of need, yet available resources were severely limited. A primary source of ethical questions for participants related to how limited resources were allocated. An expatriate participant described some of these tensions, asking

When you have limited resources, how do you decide who is in more need? What is the most equitable way of providing and sharing the resources that you have... when there is clearly more need than the resources available?

Participants struggled with the need to prioritise in order to distribute the limited resources; they questioned both how this ought to be done and the decisions that were actually made.

In their accounts, participants reported various approaches for allocating resources between individuals in need. In the acute relief phase, the majority of participants described approaches prioritising individuals most likely to survive, including situations when those less likely to survive did not receive care. Participants also reported instances in which aid was provided first to individuals who were the most ill or injured. In yet other situations, participants described that, due to the scale of need, a less deliberate and more opportunistic approach was enacted and the needs of individuals closest at hand were addressed first without consideration of whether others might be more in need. Participants discussed how, at a broader level, the mandates of some organisations directed them to prioritise their efforts towards specific groups identified according to categories linked to notions of vulnerability (such as women, children or persons with disabilities). Concerns were raised, however, when prioritisation models seemed more aligned with donor priorities or topics of focus for the media than on what the participants saw as the most pressing needs.

For participants, defining vulnerability or estimating relative levels of need posed particular difficulties. Multiple factors contributed to these challenges. One concern related to population needs in neighbourhoods less affected by the earthquake. An expatriate participant reported that some of these areas were in reality among the most destitute, with individuals living in them sometimes experiencing much higher levels of vulnerability than many earthquake survivors who lived in neighbourhoods that were harder hit. Often those in the poorer yet less directly affected neighbourhoods were not eligible for disaster-related assistance even when they requested it, thereby causing ethical distress for responders who viewed them as equally as, if not more vulnerable than, earthquake victims.

Overall, participants struggled with the need to select who would receive assistance due to the depth and varied sources of vulnerability that they encountered. In light of overwhelming needs and limited resources, participants expressed that having a deliberate strategy for prioritisation was necessary. Many felt uncomfortable however with the ways that such strategies also resulted in the exclusion of individuals whom the participants considered to be highly vulnerable but whose situation of need was exacerbated by, but not directly resulting from, the physical damage of the earthquake.

\section{At what point does it become ethically problematic to expend (often considerable) resources to sustain disaster responders who come from other countries?}

A second question related to the dedication of scarce resources to international responders. Concerns were raised by both expatriate and Haitian participants about the type of housing and security provided to expatriates in contrast to living conditions experienced by Haitians involved in the aid response, or by the local community more generally. Such differences were particularly evident between Haitian and expatriate individuals who were working side by side in the response. One expatriate responder expressed discomfort saying

it was really disturbing to me... because as an international, we would be housed in really, quite nice facilities that had survived the earthquake, were protected areas. And provided great resources to be able to do our work... because it is a liability for an organization to send people in. So they have to worry about all of the provisions of food and shelter, and safety for their international employees. And yet we hire national employees to do a lot of the labor, and they aren't necessarily compensated in the same way, and we certainly were working alongside people who were living in really terrible situations

Participants described discrepancies between the living conditions experienced by expatriate and Haitian individuals involved in the response, and seven participants described concerns more generally about the amount of resources expended to provide shelter and protection to expatriate responders. One aspect of 
this situation was the impact of NGOs paying elevated rents for housing, which the participants associated with increased costs of housing for Haitians.

The amount of resources expended to provide for expatriate responders, and inequalities identified between local and expatriate responders, were troubling for several participants. These prompted concern related to equity in how disaster relief is organised and implemented.

\section{How ought rapid and reactive interventions be balanced with more deliberated and coordinated approaches?}

Given the overwhelming and obvious needs, there was a strong impetus for responders to take immediate action to help vulnerable individuals in close proximity during the acute phase of the disaster. Such immediate and reactive interventions were contrasted with a more coordinated response that, according to many participants, could have ultimately met the needs of more acutely injured individuals or the needs of more people. It was recognised however that greater coordination in the acute phase would have required time to evaluate vulnerabilities and organise services in consequence, thus decreasing the speed of the initial response.

Tensions between immediate action and a more coordinated response were also discussed in relation to the extremely limited services provided in some of the hardest hit areas that were outside the city of Port-au-Prince, and closer to the earthquake's epicentre. Participants reported that in the haste to provide prompt assistance, the lack of information and coordination delayed the provision of aid to these areas.

Acting to meet immediately apparent needs but lacking a broader sense of the distribution of damage and need was also reflected in individual responders' actions. An expatriate participant suggested however that focusing on immediate needs could also be a means of coping and preventing being paralysed by the knowledge of the overwhelming extent of need:

There were doctors who said, No, no I will give maximum attention to this one patient who was in the waiting room ... and not wanting to touch the issue of all the patients waiting because that was beyond that imaginable.

Participants reported experiencing distress as the extent of need seemed unknowable and greater than what could be addressed. This situation thus led some responders to narrow their attention to the immediate surroundings while excluding consideration of the broader context.

All participants felt overwhelmed by the vast and intense levels of need. Many reported providing assistance as best they could without a clear sense of how their resources might be most effectively used. They struggled with the knowledge that this approach meant that some individuals with greater needs likely did not receive services.

\section{What trade-offs are justified when interventions to address acute needs could contribute to longer-term vulnerabilities?}

Hundreds of international NGOs mobilised staff and brought in supplies to provide assistance to those affected by the earthquake. Participants reflected on a range of broader consequences related to this influx of assistance and the models that were implemented for its organisation and distribution. A recurring concern was the role to be played (or lack thereof) by Haitian institutions and, in particular, the Haitian government in the earthquake response. Participants raised questions about the legacy of acute responses and the possibility of contributing to long-term vulnerability or missed opportunities to support and develop local capacity.

Participants reflected on the effects of NGOs working separately from local government and agencies. While acknowledging struggles related to coordination and the fragility of local structures, sidestepping local actors was identified as either a missed opportunity to address future vulnerabilities or as actually contributing to them. A range of long-term consequences were identified. For example, several Haitian participants reported that free care provided by NGOs for an extended period of time created an expectation of continued free healthcare while also leading to the closure of many for-profit health clinics. These closures created a gap in the health system and increased vulnerability in the long term as there were fewer clinics to meet healthcare needs when NGOs ended their projects.

Participants discussed how the tendency to exclude or sidestep local actors fit with a broader pattern related to the power of international organisations and relative disempowerment of governmental and non-governmental actors within Haiti. Eight participants reported that this pattern had a negative impact on Haitian society after the earthquake. As one Haitian participant expressed, "the Haitian society needed to be rebuilt, needed to regain confidence in itself and to feel power over its well-being. It is a rebuilding of society and it comes with education, dignity, rights and responsibility". Both expatriate and Haitian participants expressed that greater involvement of Haitians in decision-making roles would have led to a response that better reflected needs and local realities.

Working outside of, or circumventing, local structures may have led to greater short-term efficiency but participants, both Haitian and expatriate, saw this approach as a missed opportunity to reduce future vulnerabilities, and may sometimes have exacerbated existing, or even created new sources of, vulnerabilities.

\section{DISCUSSION}

The four questions identified in this study share a common source; they all arise in light of an immense gap between the limited available resources and the widespread and elevated needs experienced by the population. The shortage of resources in the face of great needs and the necessity of responding quickly have been recognised as common sources of ethical challenge in humanitarian aid. ${ }^{1}$ Disaster relief efforts in a context of high levels of pre-existing vulnerability, in addition to vulnerability related to the disaster itself, present a more complex situation, however, than a mere case of identifying the best strategy for the distribution of goods. Limited resources in this case included consumables such as food, clean water and medicine, temporary and permanent shelter, and a wide range of human resources. The resource limitations also occurred in a context that was chaotic and quickly changing, where information and coordination were limited, and where levels of pre-existing vulnerability were very high.

\section{Prioritising quickly with insufficient information}

In situations of acute need and scant resources, such as in the days and weeks following a major disaster, there will inevitably be challenges associated with providing a rapid response, ${ }^{4}$ especially when information is fragmented, contradictory or inaccurate. A truly coherent response strategy requires an understanding of the local context and the unfolding situation. ${ }^{25}{ }^{26}$ As Ahmad et al state, "if aid is not provided according to need, further harm can occur to those with the greater needs who do not receive sufficient aid...Providing aid 
according to need necessitates prior understanding of people's needs".[ref. 25, p. 101] This observation echoes the study participants' distress at not having enough information to provide the most effective response.

Acting with limited information about where there is the greatest level of need, what type of vulnerability is being encountered and what is the best way to address the needs in this cultural context is a common occurrence in the acute phases of humanitarian responses. ${ }^{27}$ The acuity of the disaster however can lessen the perceived priority of a more comprehensive needs assessments, and furthermore the nature of the situation can render it nearly impossible to collect the necessary information to guide a more effective and coordinated response. $^{25} 2728$ Although participants acknowledged that the assistance they provided was not part of a well-coordinated response, they did not feel developing better coordination mechanisms fell within their individual responsibilities, nor that it could have been easily achieved in the moment. The lack of coordination in the response and the resulting difficulties have been widely documented. ${ }^{29}$

\section{Prioritisation and trade-offs}

Discussions related to the process of determining which needs to prioritise are prominent in the disaster-response literature and occur at both micro (eg, at the bedside) and broader macro (eg, between projects) levels. ${ }^{1-7} \mathrm{~A}$ key example of prioritising scarce resources at the micro level is triage. Barilan $e t a l^{2}$ discuss the difficulty that triage presents for responders:

conversations with rescue teams bring forth the agony of triage. Relief workers and healthcare professionals are troubled by "no treatment" decisions and are haunted by flashbacks of rejected victims... the special circumstances of disaster medicine render triage in disaster care a special sub-set of moral, clinical and psychological problems.[pp. 49-50]

The struggles described by these authors are similar to those expressed by the study participants. In light of the limitations, humanitarian responders grapple with decisions about how resources should be distributed. In such situations, allocating aid inevitably comes at the expense of not helping some individuals who are in acute need, resulting in ethical distress in the moment and feelings of regret later.

On a broader scale, a particularly complex aspect of disasterresponse situations involves taking into account potential sources of long-term vulnerability while providing aid to address acute vulnerabilities in the wake of the disaster. Pre-existing vulnerabilities, often compounded by the disaster, also need to be considered. In Haiti, high levels of pre-existing vulnerability due to poverty, political instability and reliance on international aid contributed to the degree of vulnerability experienced by the population following the earthquake. As is expressed by the Inter-Agency Standing Committee (IASC),

\footnotetext{
in a highly complex context such as Haiti, the humanitarian community is faced with challenging dilemmas in the provision of assistance, not least in identifying the most vulnerable and in distinguishing between those affected by the earthquake and those - the majority of the population in this instance-suffering from more systemic forms of deprivation.[ref. 29, p. 2]
}

As reported by the study participants, these realities posed challenges in determining the best use of limited disasterresponse resources in light of the varied sources of vulnerability, including determining which vulnerabilities should be left to be addressed at a later time, or by different organisations or individuals. Making such choices was often experienced as vexing and difficult.

There were also broader questions about how rebuilding efforts could be better coordinated between the international humanitarian relief agencies, and local governmental institutions and civil society organisations. The IASC similarly reported that 'an equally challenging question relates to identifying and strengthening the linkages between the relief operation and the long-term reconstruction and development agenda'.[ref. 29, p. 2] Participants reflected that immediate action, which prioritised addressing acute vulnerability but did not include local institutions, was sometimes necessary but had long-term consequences. Such actions came at the expense of contributing to building local capacity and thus, may well have reinforced or even created new sources of long-term vulnerability. Similar trade-offs were identified in retrospective analysis of the 2004 Indian Ocean Tsunami, where interventions launched by some international organisations undermined efforts by local organisations, setting back local development. ${ }^{30}$ Many authors ${ }^{18} 2526$ emphasise that the response to a disaster must take a farreaching perspective that is attentive to both long-term and short-term concerns, and considers the context as well as how the local communities can be involved and empowered. These authors acknowledge, however, that this is difficult in the midst of an acute crisis and with limited accurate information.

\section{Power differentials}

Another aspect of humanitarian crises that may be a source of ethical distress for those involved in international response efforts is related to differences in power that inevitably arise in the interactions at the core of humanitarian assistance. ${ }^{8}$ Fassin argues that 'humanitarianism, independently of the goodwill of the rescuers, constructs an unequal relationship between the one giving aid and the one being aided'.[ref. 9, p. 193] The unequal relationships highlight the different levels of vulnerability inherent in these individuals' circumstances, especially for expatriate responders and local recipients of aid, and also the different levels of power imbued by these roles. ${ }^{8-10}$ In this situation, expatriate healthcare professionals were evidently much less vulnerable than the citizens of Haiti. They had resources that enabled them to choose to come to the disaster situation and could leave if the situation became dangerous or overwhelming. Despite this difference in pre-existing vulnerability, as several participants reported, considerable resources were expended to provide shelter and sustenance to expatriate workers. This reality was seen as raising concerns relative to the support available to Haitian responders and others affected by the disaster. In a context where some earthquake victims were not prioritised for aid and many did not receive prompt assistance, additional resources provided for expatriate helpers were seen as problematic.

\section{CONCLUSION}

Priority-setting, gaps in information and coordination, power differentials and trade-offs between addressing acute or longterm vulnerability can all be sources of ethical distress for disaster responders and policy-makers, yet these challenges, and the ethical distress that they may engender, are likely unavoidable in situations of humanitarian response to crisis. The analysis presented in this paper empirically demonstrates these important ethical considerations as framed around four prominent ethical questions. Discussing these questions can help advance understanding of how relief efforts can best be designed and implemented to meet the needs of vulnerable individuals, how diverse forms of vulnerability can be considered and how to 
prioritise between competing needs during and after disasters, in an effort to minimise ethical challenges. Analysis of these issues could also be integrated into humanitarian response training with the goal of prompting reflection around key ethical questions that future responders will likely ask as they seek to assist populations in the aftermath of a disaster.

Twitter Follow Evelyne Durocher @.

Acknowledgements We gratefully acknowledge the Unité de Recherche et d'Action Médico Légale for its support and the study participants for taking part in this research. We thank members of the Global health, Ethics and Rehabilitation Works-in-Progress Group at McGill University for their feedback on an earlier version of this manuscript.

Funding This study was conducted as part of the Montreal Health Equity Research Consortium through a grant from the Canadian Institutes of Health Research (ROH 115214). MH is supported by a research scholar award from the Fonds de Recherche du Québec-Santé. ED postdoctoral fellowship was supported by the Montreal Health Equity Research Consortium, a grant from the Canadian Institutes of Health Research (EOG-120255), and the Foundation of the Jewish Rehabilitation Hospital.

Competing interests None declared.

Ethics approval REBs at McGill University, University of Montreal and National Bioethics Committee of Haiti.

Provenance and peer review Not commissioned; externally peer reviewed.

Data sharing statement The unpublished data from the study are available to the members of the research team who are listed as authors on this paper. The data are being written up into manuscripts as described in the cover letter.

\section{REFERENCES}

1 Schwartz $\mathrm{L}$, Sinding $\mathrm{C}$, Hunt $\mathrm{M}$, et al. Learning from the narratives of humanitarian health workers. Am J Bioethics 2010;1:45-54.

2 Barilan Y, Brusa M, Halperin P. Triage in disaster medicine: ethical strategies in various scenarios. In: O'Mathuna D, Gordijn B, Clarke M, eds. Disaster bioethics: normative issues when nothing is normal. New York, NY: Springer Science, 2014:49-63.

3 Sinding C, Schwartz L, Hunt M, et al. 'Playing God because you have to': health professionals' narratives of rationing care in humanitarian and development work. Public Health Ethics 2010;3:147-56.

4 Merin O, Ash N, Levy G, et al. The Israeli field hospital in Haiti-ethical dilemmas in early disaster response. New Engl J Med 2010;362:e38.

5 Ford N, Zachariah R, Mills E, et al. Defining the limits of emergency humanitarian action: where, and how, to draw the line? Public Health Ethics 2010;3:68-71.

6 Rubenstein J. The distributive commitments of international NGOs. In: Weiss T, Barnett M, eds. Humanitarianism in question. Ithaca, NY: Cornell University Press, 2008:215-34.

7 Ten Have H. Macro-triage in disaster planning. In: O'Mathuna D, Gordijn B, Clarke $\mathrm{M}$, eds. Disaster bioethics: normative issues when nothing is normal. New York, NY: Springer Science, 2014:13-32.

8 Fassin D. Humanitarianism as a politics of life. Public Cult 2007;19:499-520.

9 Fassin D. Humanitarian reason. Berkeley, CA: California University Press, 2010.
10 Redfield P. The unbearable lightness of ex-pats: double binds of humanitarian mobility. Cultural Anthropol 2012;27:358-82.

11 Hunt M, Sinding C, Schwartz L. Tragic choices in humanitarian healthcare practice. J Clin Ethics 2013:23:338-44.

12 Adger N. Vulnerability. Glob Env Change 2016;16:68-281.

13 Hurst SA. Vulnerability in research and health care; describing the elephant in the room? Bioethics 2008;22:191-202.

14 Mackenzie C, Rogers W, Dodds S. Introduction: what is vulnerability and why does it matter for moral theory. In: Mackenzie C, Rogers W, Dodds S, eds. Vulnerability: new essays in ethics and feminist philosophy. Oxford: Oxford Publishing, 2014:1-32

15 Peroni L, Timmer A. Vulnerable groups: the promise of an emerging concept in European human rights convention law. Int I Const Law 2013:11:1056-85.

16 Wisner B, Blaikie P, Cannon T, et al. At risk: natural hazards, people's vulnerability and disasters. New York, NY: Routledge, 2014.

17 Dubois L. Haiti: the aftershocks of history. New York, NY: Metropolitan Books, 2012.

18 Pinto AD. Denaturalizing "natural" disasters: Haiti's earthquake and the humanitarian impulse. Open Med 2010:4:e193-6.

19 Disaster Emergency Committee. Haiti earthquake facts and figures. (n.d.) http:/l www.dec.org.uk/haiti-earthquake-facts-and-figures (accessed Apr 2015).

20 Humanitarian Communication Group. Haiti earthquake response (as of 8 Jan 2011). 2011. http://www.un.org/en/peacekeeping/missions/minustah/documents/ocha_ haiti_one_year_factsheet.pdf (accessed Apr 2015).

$21 \mathrm{O}^{\prime}$ Hagan P. An independent joint evaluation of the Haiti earthquake humanitarian response. 2010. http://www.alnap.org/resource/5969.aspx (accessed Apr 2015).

22 Hidalgo $S$. Inter-agency real-time evaluation of the humanitarian response to the earthquake in Haiti: 20 months after. 2012. http://www.alnap.org/resource/6330 (accessed Apr 2015)

23 Chung R, Hunt M, Olivier C. Montreal Health Equity Research Consortium. Opportunities and challenges for addressing health equity and vulnerability in disaster response: the case of the Haiti earthquake disaster response. 2015. http:// mherc.net/projects/exploration-of-stakeholder-perspectives-on-health-equityvulnerability-and-ethics-in-haiti-earthquake-response/ (accessed Apr 2015).

24 Thorne S. Interpretive description. Walnut Creek, CA: Left Coast Press, 2008.

25 Ahmad A, Mahmud S, O'Mathuna D. Evidence and healthcare needs during disasters. In: O'Mathuna D, Gordijn B, Clarke M, eds. Disaster bioethics: normative issues when nothing is normal. New York, NY: Springer Science, 2014:95-106.

26 Schwartz L, Hunt M, Redwood-Campbell L. Ethics and emergency disaster response. Normative approaches and training needs for humanitarian health care responders. In: O'Mathuna D, Gordijn B, Clarke M, eds. Disaster bioethics: normative issues when nothing is normal. New York, NY: Springer Science, 2014:33-48.

27 Darcy J, Hofmann C. According to need? Needs assessment and decision-making in the humanitarian sector. 2003. http://www.odi.org/sites/odi.org.uk/files/odi-assets/ publications-opinion-files/285.pdf (accessed Apr 2015).

28 Bradt DA. Evidence-based decision-making (part II): applications in disaster relief operations. Prehosp Disaster Med 2009;24:479-92.

29 Inter-Agency Standing Committee. Response to the humanitarian crisis in Haiti: following the 12 January 2010 earthquake. 2010. http://www.humanitarianinfo.org/ iasc/pageloader.aspx?page=content-news-newsdetails\&newsid=143 (accessed Apr 2015).

30 Telford J, Cosgrave J. The international humanitarian system and the 2004 Indian Ocean earthquake and tsunamis. Disasters 2007:31:1-28. 